\title{
Leitura e Teatro: primeiras aproximações
}

\author{
Heloise Baurich Vidor \\ Doutoranda em Artes Cênicas/USP \\ Área de Concentração: Pedagogia do teatro \\ Orientadora: Maria Lúcia de Souza Barros Pupo \\ Professora Assistente da Universidade do Estado de Santa Catarina (UDESC)
}

Resumo: As possibilidades poéticas e pedagógicas que se abrem a partir da aproximação entre teatro e leitura de textos é o ponto de partida desta investigação. A supervisão da prática dos estagiários do curso de Licenciatura em Teatro da UDESC/SC revelou que um dos desafios do ensino do teatro é a apropriação do texto escrito por um autor pelo aluno-ator. Pretende-se propor a exploração lúdica da leitura de textos como caminho potencialmente fértil para o percurso do 'escrito ao dito'. A dimensão oral da leitura (Bajard, 2005) e sua relação com o teatro - a partir da revisão dos conceitos de leitura dramática e de leitura cênica (Pavis, 2010), abordagem contemporânea subsidiarão a experimentação prática em contextos diferenciados de ensino do teatro.

Palavras chaves: Aluno-ator, fala, leitura cênica, pedagogia do teatro

Title: Reading and Theatre: first approaches

Abstract:The poetic and pedagogical possibilities that are opened from the rapprochement between theatre and text reading is the starting point of this research. The supervision of the UDESC/SC Drama course degree trainees' practice revealed that one of the challenges encountered in the teaching of theatre is the ownership of a text written by an author, by the student-actor. We intend to propose a playful exploration using the reading of texts as a potentially fertile path from "written to said". The oral dimension of reading (Bajard, 2005), its relationship with theatre - starting from the revision of concepts such as dramatic reading and its contemporary approach to scenic reading (Pavis, 2010) will provide practical experimentation in different contexts within the teaching of theatre.

Keywords: Scenic reading, speech, student-actor, theatre pedagogy

Título: La lectura y el teatro: primeras aproximaciones

Resumen: Las posibilidades poéticas y pedagógicas que se abren a partir del acercamiento entre el teatro y la lectura de textos, es el punto de partida de esta investigación. La supervisión de la práctica docente de los alumnos del curso de Licenciatura en Teatro de la UDESC/SC reveló que uno de los desafíos de la enseñanza de teatro es la apropiación del texto, escrito por un autor, por el alumno-actor. La intención es proponer la exploración lúdica de la lectura de textos como camino potencialmente fértil para el recorrido de lo 'escrito a lo dicho'. La dimensión oral de la lectura (Bajard, 2005), y su relación con el teatro - desde la revisión de los conceptos de lectura dramática y de lectura escénica (Pavis, 2010), enfoque contemporáneo subsidiarán la práctica experimental en diferentes contextos de la enseñanza de teatro.

Palabras-clave: lectura escénica, habla, pedagogía de teatro, alumno-actor. 
O texto desta comunicação apresenta as inquietações que levaram ao tema do projeto de pesquisa em desenvolvimento no Programa de Pós Graduação em Artes Cênicas da ECA/USP, cujo título é A visualidade da palavra: apropriação do texto em processos pedagógicos de teatro. Este projeto propõe a investigação de procedimentos de trabalho com o texto escrito em processos de ensino do teatro, tomando o ato da leitura ${ }^{1}$ como uma das etapas primordiais neste processo, de modo a explorar sua dimensão pedagógica e também poética.

A experiência como professora do curso de Bacharelado e Licenciatura em Teatro da UDESC/SC, acompanhando a prática de ensino dos estagiários em escolas e comunidades da cidade de Florianópolis desde 2005, revelou a dificuldade enfrentada por parte de proponentes de processos pedagógicos de teatro em trabalhar com textos escritos. Quando o texto, seja dramático, narrativo ou poético, está presente, a opção recorrente de muitos destes proponentes é a de utilizá-lo como pré-texto (O’NEILL, $2005)$ - roteiro, estrutura que opera como um 'pano de fundo' - ou como estímulo inicial para a construção de um texto coletivo a partir de improvisações, ou seja, recriação do texto do autor pelo aluno - o texto neste caso deixa de existir e o que permanece é a fábula.

Quando o texto do autor, o texto original, é trazido para o processo, normalmente em pequenos fragmentos, nota-se a dificuldade que o participante, em diferentes contextos e com diferentes faixas etárias, apresenta na passagem do 'escrito para o dito', em última instância, em dizer um texto que não é seu, com o mesmo prazer e fluência com que diz um texto improvisado. Seja para manter o texto, seja para recriálo, outro fator observado é que o espaço reservado para a leitura do texto no processo teatral é mínimo e um tanto atropelado.

Estas constatações abrem espaço para algumas suposições sobre o tema: a dificuldade do aluno com a leitura/letramento, dificuldade esta anterior ao momento da experiência teatral propriamente dita; a dificuldade gerada pela falta de paciência do aluno e do professor com um tipo de trabalho que requer tempo lento, esforço, certa imobilidade física, ainda mais se tiver que trabalhar com um texto na íntegra, já que há uma tendência atual de trabalhar com adaptações ou versões dos textos narrativos e/ou dramáticos nas aulas de literatura na tentativa de facilitar o trabalho do leitor.

A respeito das dificuldades que os alunos enfrentam com a leitura e letramento, Élie Bajard (2005) reflete sobre a importância da dimensão oral da leitura e sua função 
social e comunicativa na conquista da língua escrita. Para Bajard, "é necessário fazer do dizer uma das grandes práticas da língua escrita, [e que] não pode desaparecer quando se instala o domínio da leitura" (2005, p. 80). A busca pela gênese da dificuldade com a leitura, enfrentada por grande parte dos estudantes, pode nos remeter às questões relacionadas com a alfabetização.

Se "dizer" é a atividade de comunicação vocal de um texto escrito, que comporta uma dimensão lúdica, "que obriga aquele que diz a assumir pessoalmente as diversas instâncias de enunciação, e o transforma em personagens" (BAJARD, 2005, p. 82), voltamos ao teatro e ao seu potencial para reforçar a dimensão oral enfatizada pelo autor.

Mas, se o professor parte do princípio de que os alunos não gostam de ler, supõe então que num processo de teatro não teria sentido insistir na leitura, pois eles passariam a não gostar do teatro também. Como aliar a leitura à prática teatral? Sem saber como conduzir esse processo de apropriação das palavras de forma que transcenda a abordagem técnica - que não se sustenta numa perspectiva de trabalho com não atores - o professor de teatro prefere não debruçar-se sobre esta tarefa.

Diante deste quadro, propomos, inicialmente, um olhar para as relações entre leitura e teatro, de modo a encontrar pistas sobre o potencial desta união para o enfrentamento da situação observada na prática pedagógica.

\section{Leitura e Teatro}

A relação da leitura com o teatro, até pouco tempo, era associada aos formatos de leitura de mesa - exercício de "embocadura" para a fala (Kosovski, 2009) - ou leitura dramática - que tem objetivo de divulgar a obra de novos dramaturgos. Na cena contemporânea, entretanto, podemos observar uma modalidade de leitura que ocupa uma posição de fronteira com o espetáculo propriamente dito. Esta modalidade é denominada leitura cênica_(PAVIS, 2010). Entre a leitura dramática e a encenação, na leitura cênica, apesar de os atores sustentarem o 'texto em mãos', nota-se claramente uma concepção de direção, com acabamento plástico e sonoro.

Cartas a Génica - espetáculo no qual a atriz Carole Bouquet lê poemas, textos e cartas do teatrólogo Antonin Artaud; Celebration of Harold Pinter - espetáculo dirigido por John Malkovich, em que Julian Sands lê as poesias do dramaturgo inglês; 
História de amor (Últimos capítulos) - leitura cênica do texto de Jean-Luc Lagarce realizada pelo Teatro da Vertigem; A filha do teatro - leitura cênica do texto de Luís Augusto Reis, com direção de Edélcio Mostaço - da qual pude participar como atriz são alguns exemplos de criações que aliam leitura de texto e teatro, levando a cabo uma proposta espetacular.

A oportunidade de participar da leitura cênica do texto de Luís Augusto Reis revelou-nos a peculiaridade deste formato e as possibilidades que surgem quando a leitura do texto pelos atores é preservada na finalização do trabalho. O desenho das cenas, a utilização de imagens projetadas, figurino, e um processo de aproximadamente um mês de ensaios, nos fizeram pensar que A filha do teatro era mais que uma leitura dramática. Era um esboço do espetáculo, no qual as atrizes estavam com o 'texto em mãos', ou era o próprio espetáculo?

Em termos da atuação, a relação da leitura cênica e pública com a representação estabeleceu uma variação apenas de grau. Sobre isso, Patrice Pavis comenta: "a leitura não se faz necessariamente encolher com relação à atuação: a atuação pode ser muito discreta, ao passo que a leitura é, por vezes, histriônica." (PAVIS, 2010, p. 27).

Se a relação com a representação se mantém, se a concepção do espetáculo está presente, com acabamento visual e sonoro, e se, conforme o próprio Pavis (2010, p. 25) diz que "Reencontrar a simplicidade da leitura parece-lhe ser a tarefa mais urgente [do teatro]" , então por que espetacularizar a leitura? Ou, colocado de outra forma, por que fazer com que os atores sustentem o 'texto em mãos' em uma concepção de apresentação pública nos moldes conhecidos do espetáculo?

Remetendo-nos a seu formato mais simples, encontramos a leitura compartilhada ou pública que, em termos de aproximação com a representação, ocuparia, numa escala de valores, o extremo de menor valor. Empreendida, frequentemente por educadores interessados no tema da formação de leitores ou estudiosos de literatura, a leitura pública já possui adeptos em diferentes localidades. Marc Roger e Jean Guiet na França, Alma Velasco no México, Gustavo Bombini na Argentina, e Lucila Pastorello ${ }^{2}$ no Brasil, são alguns dos nomes relacionados a esta modalidade. Organizando eventos e cursos de formação para leitores públicos, podemos dizer que estes leitores transitam de alguma forma pelas artes da cena. 
Para Paul Zunthor, a leitura em voz alta, visualizada por uma pessoa ou por uma audiência, seria uma modalidade que apresenta a característica performancial da leitura, pois, segundo este autor, a situação performancial está presente, inclusive, na leitura silenciosa, já que "entre o consumo [...] de um texto poético escrito e de um texto transmitido oralmente, a diferença só reside na intensidade da presença” ( 2007, p. 69).

Já para Denis Guénoun, “fazer ouvir um texto é fazer dele uma leitura pública, em voz alta. Uma leitura, mesmo pública, não é teatro. É uma atividade que mantém com o teatro laços profundos e complexos [...] mas ela é infra, extra, ou prototeatral: como preferirem: não é exatamente teatral" ( 2003, p. 44) e segue:

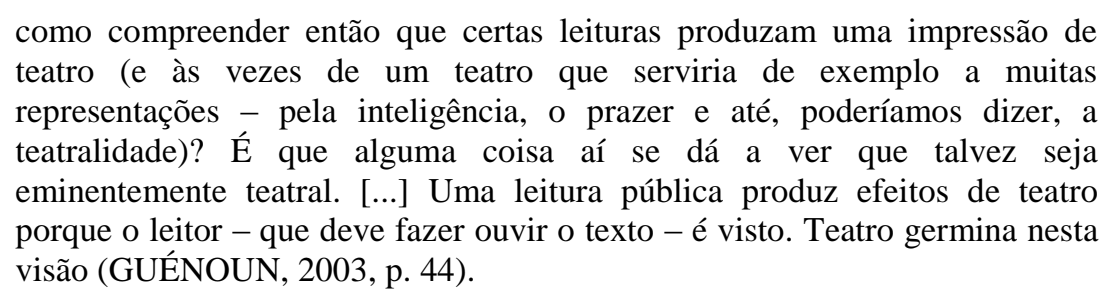

Portanto, os conceitos que amparam o parentesco entre leitura e teatro parecem residir nas noções de 'caráter performancial da leitura' e de 'intensidade da presença', colocadas por Zunthor (2007), e a 'visualidade do leitor e da palavra', segundo Guénoun (2003), seja diante de um espectador ou de uma audiência. Estas colocações são interessantes quando relacionadas ao âmbito pedagógico, pois a experimentação com o 'caráter performancial' da leitura pode ser realizada de modo flexível, variando gradualmente sua relação com a representação, conforme o contexto em que se dá o trabalho.

Mais do que analisar os laços complexos entre o teatro e a leitura em voz alta, tentando decifrar o que Guénoun quer dizer com "infra, extra, ou prototeatral, mas não exatamente teatral", nossa investigação pretende propor experimentações práticas com leituras com o intuito de que estas leituras, como diz Guénoun, "produzam uma impressão de teatro (e às vezes de um teatro que serviria de exemplo a muitas representações - pela inteligência, o prazer e até, poderíamos dizer, a teatralidade", em contextos diferenciados, que aliem teatro e pedagogia e favoreçam o trabalho com a apropriação do texto.

\section{Considerações finais}


Estas reflexões iniciais apontam para as diferentes possibilidades existentes entre leitura e teatro, mostrando que o caráter performancial existente, inclusive na leitura silenciosa, é o fator que abre espaço para a aproximação destes campos. A intensidade do caráter performancial da leitura pode variar e esta variação é o que acentua a distância da leitura em relação à noção de representação.

Assim, abre-se um campo para a experimentação que, indo de um extremo a outro na escala, pode transitar desde o formato de leitura em voz alta compartilhada com um ouvinte (no extremo mais afastado da representação), passando pela leitura pública, leitura dramática e alcançando sua versão espetacular, no extremo oposto, aos moldes da leitura cênica.

Nosso desafio será verificar as implicações de se trabalhar com o 'texto em mãos', suas possibilidades para a criação da cena e para o processo de apropriação do texto escrito pelo aluno, lidando com a condição intrínseca a esta empreitada, que alia duas ações - 'ler' e ‘fazer teatro' - cujos verbos não suportam o imperativo.

\section{Referências}

BAJARD, E. Ler e dizer: compreensão e comunicação do texto escrito. São Paulo: Cortez, 2005.

COELHO, T. Dicionário crítico de política cultural. São Paulo. Ed. Iluminuras, 2004.

FÉRAL, J. Teatro performativo e pedagogia. Sala Preta, São Paulo, Escola de Comunicações e Artes, Universidade de São Paulo, n. 09, p.255-267, 2009.

GUÉNOUN, D. A exibição das palavras: uma idéia (política) do teatro. Rio de Janeiro: Teatro do Pequeno Gesto, 2003.

KOSOVISKI, R. A mesa para a cena? Olhares, São Paulo, Escola Superior de Artes Célia Helena, n. 1, p. 62-65, 2009.

MINISTÉRIO DA EDUCAÇÃO E CULTURA. Parâmetros Curriculares Nacionais Ensino Médio. Linguagens, códigos e suas tecnologias. Brasília, 1999.

O’NEILL, C. Drama Worlds - a framework for process-drama. Portsmouth,NH: Heinemann, 2005.

PAVIS, P. A encenação contemporânea: origens, tendências, perspectivas. São Paulo: 
Revista "AspaS" - № 1 - 2011 - Anais do Primeiro Seminário de Pesquisas em Andamento uspac do Programa de Pós-Graduação em Artes Cênicas da Universidade de São Paulo.

Perspectiva, 2010.

TIOLLENT, M. Metodologia da pesquisa ação. São Paulo: Cortez, 1987.

ZUMTHOR, P. A letra e a voz - A "literatura"medieval. São Paulo: Cia das Letras, 1993.

Performance, recepção, leitura. São Paulo: CosacNaify, 2007.

.

${ }^{1}$ É importante delimitar que o sentido de 'leitura' com o qual estamos trabalhando é o sentido estrito do
termo, ou seja, recepção do escrito e não com a perspectiva de leitura da obra, campo da recepção teatral
(COELHO, 2004). Além da recepção do escrito, nossa proposta abarca a dimensão oral da leitura, ou seja,
a comunicação do escrito, e não a sua possibilidade individual e silenciosa.
${ }^{2}$ Lucila Pastorello é criadora da Cia. De Leitores Públicos - www.leitorespublicos.com.br em parceria
com a fonodióloga e professora de voz Mônica Montenegro. A Cia De Leitores Públicos desenvolve
projetos de formação, pesquisa e difusão da leitura em voz alta. 